\title{
Homology Modelling and Docking Studies of Human a2-Adrenergic Receptor Subtypes
}

\author{
Archana Jayaraman, Kaiser Jamil and Kavita K Kakarala*
}

Centre for Biotechnology and Bioinformatics (CBB), School of Life Sciences, Jawaharlal Nehru Institute of Advanced Studies (JNIAS), Secunderabad, Andhra Pradesh, India

\begin{abstract}
a2-adrenergic receptors play a key role in the regulation of sympathetic system, neurotransmitter release, blood pressure and intraocular pressure. Although a2-adrenergic receptors mediate a number of physiological functions in vivo and have great therapeutic potential, the absence of crystal structure of $\alpha 2$-adrenergic receptor subtypes is a major hindrance in the drug design efforts. The therapeutic efficacy of the available drugs is not selective for subtype specificity ( $\alpha 2 a, \alpha 2 b$ and $\alpha 2 c$ ) leading to unwanted side effects. We used Homology modelling and docking studies to understand and analyze the residues important for agonist and antagonist binding. We have also analyzed binding site volume, and the residue variations which may play important role in ligand binding. We have identified residues through our modelling and docking studies, which would be critical in giving subtype specificity and may help in the development of future subtype-selective drugs.
\end{abstract}

Keywords: a2 Adrenergic receptors; GPCRs; Homology modelling; Glide docking

\section{Introduction}

Alpha2-adrenergic receptors ( $\alpha 2$-ARs) belong to adrenergic receptor family. There are nine representative members is adrenergic family namely, $\alpha 1 \mathrm{a}, \alpha 1 \mathrm{~b}, \alpha 1 \mathrm{~d}, \alpha 2 \mathrm{a}, \alpha 2 \mathrm{~b}, \alpha 2 \mathrm{c}, \beta 1, \beta 2$, and $\beta 3$. The rationale for classification of adrenergic receptors initially was by agonist and antagonist binding characteristics, but later on they were identified as separate gene products, as reviewed by Blyund et al. [1]. $\alpha 2 a, \alpha 2 b, a 2 c$ are expressed in various organs. The relative distribution of these receptors is as follows: Brain $>$ spleen $>$ kidney $>$ aorta $=$ lung $=$ sk eletal muscle>heart=liver (IUPHAR database ) [2]. Specific functions are associated with each subtype: $\alpha 2 a-A R s$ are involved in regulation of cardiovascular function, blood pressure and plasma noradrenaline (norepinephrine). Peripheral $\alpha 2 \mathrm{~b}-\mathrm{ARs}$ are responsible for causing sodium retention and vasoconstriction, thus are involved in mediating hypertension through stimulation by agonists and salt, vasoconstrictor response and may play a role in development and reproduction $[3,4]$. Peripheral a2c-ARs causes cold-induced vasoconstriction and are involved in responses to stress, locomotion, startle reflex and it also regulates the catecholamine release from the adrenal gland, through a feedback mechanism [5,6]. a2a- and $\alpha 2 \mathrm{c}$-ARs are also involved in regulating norepinephrine release from the peripheral sympathetic neurons and thus act as presynaptic inhibitors [5]. Thus, a2-ARs serve as important drug targets against hypertension, cardiovascular dysfunction, regulating vasoconstriction, opiate withdrawal, alcohol addiction and as adjuvants for anesthesia during surgery $[7,8]$. Subtype specific drugs for $\beta 1$ and $\alpha 1$ receptors, are available, but for $\alpha 2$ adrenergic receptors the efforts are on, yet not much progress has been achieved. Still, the treatment with nonspecific drugs like Clonidine, Medetomidine, and Brimonidine are in use for the treatment of hypertension, glaucoma, tumor pain, postoperative pain etc. [9]. Most of the time the treatment with a2-receptor agonists is withdrawn due to side effects such as sedation in hypertension. Thus, the availability of subtype specific ligands would be beneficial for the treatment of diseases related to a2-receptors. But the success of drug design efforts is achieved only in the presence of high resolution crystal structure. In the absence of high resolution crystal structure, Homology modeling is an attractive method to obtain the structure, and this method has been proved to be a suitable option to get atomic level resolution of protein structures $[10,11]$. A recent review by Costanzi et al. [12] elegantly describes the various issues related to homology modeling of GPCRs. Recent studies on homology models have demonstrated that their accuracy is comparable to the structures obtained through $\mathrm{X}$-ray crystallography [13] and the ligand binding affinity is also on par with that of crystal structures [14]. But, the accuracy of homology model is solely dependent on template and when the sequence identity is less than $30 \%$ the reliability of model decreases. However, the earlier attempts of modeling GPCRs were on bacteriorhodopsin [15]. Later on, it was Bovine rhodopsin and for many years bovine Rhodopsin has been the only GPCR with experimental structural information available, and all the homology modelling efforts were focused on this structure $[16,17]$. Homology modelling and docking studies were earlier based on bovine Rhodopsin even though it showed lower sequence identity (21\%) and lower transmembrane identity $(26 \%)$ as the availability of high resolution GPCR structures was the limitation [18-25]. This was followed by the availability of other members of GPCR family, Human $\beta 2$-adrenergic receptor [26], turkey $\beta 1$-adrenergic receptor [27], squid Rhodopsin [28], Human adenosine A2a receptor [29], chemokine CXCR4 [30], Human Dopamine D3 receptor in complex with a D2/ D3 selective antagonist Eticlopride [31], and most recently histamine H1 (H1R) [32], M3 muscarinic acetylcholine receptor [33], Mu-opioid receptor [34], a lipid G protein-coupled receptor [35], M2 muscarinic receptor [36], Kappa opioid [37], Delta opioid [38], Neurotensin receptor 1 [39], chemokine CXCR1 [40], Protease activated receptor 1 [41], 5-hydroxytryptamine $1 \mathrm{~b}$ [42], and 5-hydroxytryptamine $2 \mathrm{~b}$

*Corresponding author: Dr. Kavita Kumari K, Centre for Biotechnology and Bioinformatics (CBB), School of Life Sciences, Jawaharlal Nehru Institute of Advanced Studies (JNIAS), 6th Floor, Buddha Bhawan, M G Road, Secunderabad500003, Andhra Pradesh, India, E-mail: kavitakakarala@gmail.com

Received May 06, 2013; Accepted June 24, 2013; Published June 26, 2013

Citation: Jayaraman A, Jamil K, Kakarala KK (2013) Homology Modelling and Docking Studies of Human $\alpha 2$-Adrenergic Receptor Subtypes. J Comput Sci Syst Biol 6: 136-149. doi:10.4172/jcsb.1000111

Copyright: ( 2013 Jayaraman A, et al. This is an open-access article distributed under the terms of the Creative Commons Attribution License,which permits unrestricted use, distribution, and reproduction in any medium, provided the original author and source are credited. 
[43]. Recently, the modelling groups have used $\beta 2$-adrenergic receptor as a template to model subtypes of $\alpha$-adrenergic receptors, as it shares higher sequence identity (29-31\%) and higher transmembrane identity (37-43\%) with a2-ARs [44-46].

The structure of the Human Dopamine D3 receptor was available very recently [31]. We have modelled a2-ARs using Human Dopamine D3 receptor in complex with a D2/D3 selective antagonist (PDB ID: $3 \mathrm{PBL}$ ) as template structure. The sequence identity and transmembrane identity of Human dopamine D3 receptor ( $\alpha 2 \mathrm{a}: 34 \%, 49 \%$; $\alpha 2 \mathrm{~b}$ : $32 \%, 49 \%$; $\alpha 2$ c: $34 \%, 49 \%$ ) was higher than $\beta 2$-adrenergic receptor (PDB ID: 2RH1) (a2a: 31\%, 42\% ; a2b: 28\%,41\%; a2c: 29\%,42\%), Human Histamine H1 receptor complexed with doxepin (PDB ID: 3RZE), M3 muscarinic acetylcholine receptor (PDB ID: 4DAJ), Mu-opioid receptor (PDB ID: 4DKL), a lipid G protein-coupled receptor (PDB ID: 3V2W), M2 muscarinic receptor bound to antagonist 3-quinuclidinyl-benzilate (PDB ID: 3UON), Kappa opioid in complex with JDTic (PDB ID: $4 \mathrm{DJH})$, 5-hydroxytryptamine $1 \mathrm{~b}$ in complex with dihydroergotamine (PDB ID: 4IAQ), 5-hydroxytryptamine 2b in complex with ergotamine (PDB ID: 4IB4), Delta opioid bound to naltrindole (PDB ID: 4EJ4), Neurotensin receptor 1 in complex with neurotensin (PDB ID: 4GRV), chemokine CXCR1 in phospholipid bilayers (PDB ID: 2LNL) and Protease activated receptor 1 bound with antagonist vorapaxar (PDB ID: 3VW7) (Table 1). The models of $\alpha 2$-ARs namely $a 2-a, a 2-b, a 2-c$ were minimized and checked for stereochemical correctness then docked with ligands reported to interact with alpha adrenergic receptors using Glide. As the available models of $\alpha 2 a-, \alpha 2 b-$ and $\alpha 2 c-$ ARs was based on either rhodopsin or $\beta$-adrenergic receptor, we suggest that the model based on Dopamine may prove better than rhodopsin/ beta adrenergic based model in predicting residues important for subtype specificity, as it shares more sequence identity in the transmembrane region compared to available GPCRs.

\section{Materials and Methods}

Homology modelling was done using Modeller 9v8 [10]. The other software includes Discovery studio Visualizer 3.1 (Accelrys Software Inc, San Diego; http://www.accelrys.com) and Schrödinger (Schrödinger, LLC, New York, USA, 2012).

\section{Homology modelling}

The sequences of Human a2A (PO8913), a2B (P18089), and a2C (P18825) adrenergic receptors were retrieved from SwissProt database (http://www.uniprot.org/). The template structure and sequence of Human Dopamine D3 receptor X-ray structure complexed with a selective antagonist Eticlopride (3PBL, $2.89 \AA$ ) was downloaded from PDB (www.rcsb.org). The sequence alignment was generated with Clustal W multiple sequence alignment tool (Figure S1) [47] and manually adjusted to avoid insertions and deletions in the transmembrane regions. Modelling was done using Modeller 9v8 [10].
The modeling parameters were set to output a single best structure with the least DOPE score. The water molecules could not be included for modelling as it is homology modelling method. The final models were energy minimized using the Steepest Descent minimization method until convergence is attained using the CHARMm Force field and submitted to PSVS software suite [48] for stereochemical validation [49]. The analysis output includes constraint analysis, goodness-of-fit and structure quality scores using information from prior knowledge and verifies the normality of torsion angles, bond angles, bond lengths and distances between unbounded neighbor atoms. The analysis measures are both global and site-and specific. Ballesteros-Weinstein convention was used to assign residue positions throughout our analysis for transmembrane helices [50] as well as loop regions [22].

\section{Preparation of receptor and molecular volume calculations}

The molecular volume of models of a2-ARs was determined using Discovery Studio 3.1 (Molecular Attributes, Accelrys Inc). The molecular volumes of the binding site cavity were obtained using calculate binding site from the receptor Cavities tool in DS 3.1. We selected the eraser algorithm, provided by the software, to detect probable binding site residues in the receptor. This algorithm detects binding site cavities based on the receptor shape Venkatachalam et al. [51].

\section{Ligand selection}

Twenty four ligands (agonist (Figure 1) and antagonist (Figure 2)), were selected from the literature $[22,46,52,53]$. These ligands have been reported by the research studies to bind to and interact with the a2-AR. A set of eight agonists including endogenous ligands such as Dopamine, Adrenaline, known a 2 agonists such as Clonidine, Dexmedetomidine and subtype selective agonist Guanfacine were selected from literature for docking studies $[23,39,45]$. Sixteen antagonists including subtype specific ligands such as BRL-44408, JP-1302, OPC-2836 and others such as ARC239, Clozapine, WB4101 that have been reported to bind to $\alpha 2$ adrenergic receptors were chosen for the docking studies to analyse their interactions with the $\alpha 2$-AR models based on Dopamine receptor (PDB ID:3PBL) [22,46,52]. The 3D structures were obtained from small molecule database Pubchem, present in NCBI server (http://pubchem.ncbi.nlm.nih.gov/).

\section{Docking studies}

Ligand preparation: All the agonist and antagonist structures were prepared using LigPrep (Schrödinger, LLC, New York, USA, 2012). The ligands were checked for the three-dimensional (3D) structure, realistic bond lengths and bond angles, covalent bonds, accompanying fragments, hydrogens, protonation states and were prepared using Ligprep. The LigPrep process consists of a series of steps that perform conversions, apply corrections to the structures, generate variations on the structures, eliminate unwanted structures, and optimize the

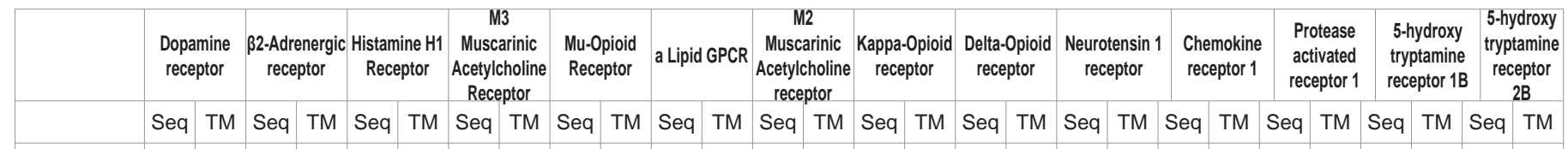

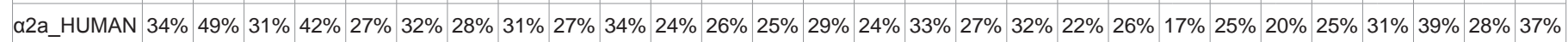

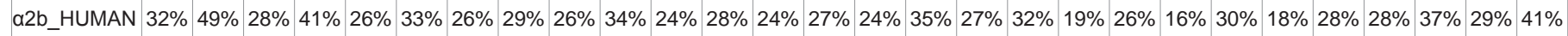

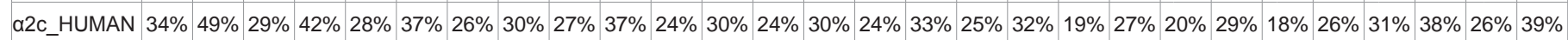
Table 1: Comparison of sequences identities of $\alpha-2$ ARs with crystal structures of Dopamine Receptor, $\beta 2$ - adrenergic receptor, Histamine $\mathrm{H} 1$ receptor, M3 Muscarinic Acetylcholine receptor, Mu-Opioid Receptor, a Lipid GPCR ( Results are based on BLAST and BLAST- 2 Analysis). 
<smiles>CC(Cc1ccccc1-c1cccc(C(=O)O)c1)C1C=CCN1</smiles>

16757182

(R)-(+)-m-nitrobiphenyline_oxalate<smiles>Brc1c(NC2=NCCN2)ccc2nccnc12</smiles>

2435

Brimonidine<smiles>NCCc1ccc(O)c(O)c1</smiles>

681

Dopamine<smiles>NCC(O)c1ccccc1</smiles>

1000<smiles>Clc1cccc(Cl)c1NC1=NCCN1</smiles>

2803

Clonidine

5311068

Dexmedetomidine

5816

Adrenaline 2-amino-1-phenylethanol<smiles>CNC[C@H](O)c1ccc(O)c(O)c1</smiles><smiles>Cc1cccc(C(C)c2cnc[nH]2)c1C</smiles><smiles>NC(N)=NC(=O)Cc1c(Cl)cccc1Cl</smiles>

3519

Guanfacine

Figure 1: Chemical structures of agonist for docking a2-ARs. Agonists were used for docking studies with $\alpha 2$ adrenergic receptor subtype models based on human Dopamine crystal structure (3PBL). The chemical structures were downloaded from Pubchem

structures. To initiate the process, the ligand structures in sdf format were used as input for the LigPrep module. The agonist and antagonist structures were prepared separately. We used the default OPLS_2005 as the Force field for minimization and the ionization states to be generated were set to the default $\mathrm{p}^{\mathrm{H}}$ of $7.0 \pm 2.5$. Ionization states were generated using Epik which generates these states in aqueous solution. We also selected the option to retain the original state of the input molecule. To ensure that other molecules such as water and counter ions are excluded from the ligand structure, we used the Desalt option in LigPrep. We selected the Generate Tautomer option to generate tautomeric forms of the input ligands. Finally, we used the Retain specified chiralities option to use the chiral information from the original ligand file after the module fixes any irregularities with regard to atom numbering and bond directions. The prepared and minimized ligands are generated as .mae outfile which is used for docking.

Protein structure preparation: The $\alpha 2$-adrenergic receptor models were prepared using protein preparation wizard of Schrödinger Maestro 9.3 (Schrödinger, LLC, New York, USA, 2012). Schrödinger offers a comprehensive protein preparation facility in the Protein Preparation Wizard, which is designed to ensure chemical correctness and to optimize protein. The protein structure pdb file was used as input for this module. In the process tab, we selected the options Assign bond orders, Add hydrogens, Create zero-order bonds to metals, create disulphide bonds, Fill in missing side chains using Prime and Delete waters beyond $5 \AA$ from hetero groups options to fix any irregularities in the structure. Finally we refined through restrained minimization using the OPLS 2005 Force field. This minimization is performed by the impref utility which uses Impact to perform minimization wherein a harmonic potential of $25 \mathrm{kcal} \mathrm{mol}^{-1} \AA^{-2}$ is used to restrain the heavy atoms.

\section{Docking}

Receptor grid generation: After ensuring that the protein and ligands were in the correct form for docking, the receptor-grid files were generated using a grid-receptor generation program. Grid was generated at the centroid of the active site residues consisting of residues D3.32 ( $\alpha 2 \mathrm{a}:$ Asp113, a2b: Asp92, a2c: Asp131), S5.42 ( $\alpha 2 \mathrm{a}$ : Ser200, a2b: Ser176, a2c: Ser214) S5.46 (a2a: Ser204, a2b: Ser180; a2c: Ser218) $[18,20,53]$. The grid box generated is of the dimensions-outer/ grid box: 30, 30, 30 and ligand centre box/inner box: 10, 10, 10 .

Ligand docking: The ligands were docked using the Glide application which uses Impact version v18007 program to perform the docking (Schrodinger, LLC, New York, USA, 2012) [54-57]. It performs grid-based ligand docking with energetics and searches for favorable interactions between one or more typical small ligand molecules and a typically larger receptor molecule, usually a protein [54]. The receptor grid generated and the prepared ligands were used as input. The ligand sampling was set to flexible which generates alternate conformations of the input ligands internally while docking and torsional sampling bias for nitrogen inversions, ring conformations and amide bonds. Since Epik was used for ionization during ligand preparation, Epik penalties were imposed during docking to compensate for higher 
<smiles>COc1ccccc1N1CCN(CCC2C(=O)c3ccccc3C(C)(C)C2=O)CC1</smiles>

609483

ARC239<smiles>CN(C)CCCN1c2ccccc2Sc2ccc(Cl)cc21</smiles>

2726

Chlorpromazine<smiles>c1ccc2c(c1)OCC(C1=NCCN1)O2</smiles>

54459

Idazoxan<smiles>CCC1(c2cnc[nH]2)Cc2ccccc2C1</smiles>

71310

Atipamezole<smiles>CN1CCN(C2=c3ccccc3=Nc3ccc(Cl)cc3N2)CC1</smiles>

2818

Clozapine<smiles>CN1CCN(c2ccc(Nc3c4ccccc4nc4ccccc34)cc2)CC1</smiles>

540335

JP-1302<smiles>COc1cc2nc(N3CCN(C(=O)c4ccco4)CC3)nc(N)c2cc1OC</smiles>

4893

15942713
OPC- 28326<smiles>O=C(CCCN1CCC2(CC1)C(=O)NCN2c1ccccc1)c1ccc(F)cc1</smiles>

5265

Spiperone
Prazosin

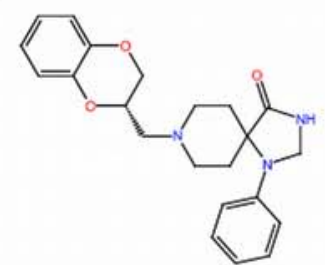

5268

Spiroxatrine<smiles>C[C@H]1c2ccccc2CN1CC1=NCCN1</smiles>

121850

BRL-44408<smiles>c1ccc2c(c1)OCC(CN1CCN(C[C@@H]3COc4ccccc4O3)CC1)O2</smiles>

94342

Dibozane<smiles>CN1CC[C@]2(CCN3CCc4c(oc5ccccc45)C3C2)N(C)C1=O</smiles>

123679

MK-912<smiles>COC(=O)[C@H]1[C@@H](O)CC[C@H]2CN3CCc4c([nH]c5ccccc45)[C@H]3C[C@H]21</smiles>

643606

Rauwolscine<smiles>COc1cccc(OC)c1OCCNC[C@H]1COc2ccccc2O1</smiles>

5685

WB4101<smiles>COC(=O)[C@H]1[C@@H](O)CC[C@H]2CN3CCc4c([nH]c5ccccc45)[C@H]3C[C@H]21</smiles>

Figure 2: Chemical structures of antagonist for $\alpha 2$-ARs. Antagonists were used for docking studies with $\alpha 2$ adrenergic receptor subtype models based on human Dopamine crystal structure (3PBL). The chemical structures were downloaded from Pubchem. 
energy states. The default OPLS_2005 Force field was used for docking. The ligands were docked with the active site using the 'extra precision' Glide algorithm. The default van der Waals scaling factor of 0.8 with a partial charge cutoff of 0.15 were used to reduce penalty for close contacts for non-polar ligand atoms in the ligand tab of the glide panel. Glide generates conformations internally and passes these through a series of filters. It first places the ligand centre at various grid positions of a $1 \AA$ grid and rotates it around the three Euler angles. At this stage, crude score values and geometrical filters weed out unlikely binding modes. The next filter stage involves a grid-based force field evaluation and refinement of docking solutions including torsional and rigid body movements of the ligand. The final energy evaluation is done with GlideScore and a single best pose is generated as the output for a particular ligand.

GScore $=\mathrm{a}^{*} \mathrm{vdW}+\mathrm{b}^{*}$ Coul + Lipo + Hbond + Metal + BuryP + RotB + Site where, $\mathrm{vdW}=>$ van der Waal energy; Coul => Coulomb energy; Lipo $\Rightarrow$ lipophilic contact term; HBond $=>$ hydrogen-bonding term; Metal $=>$ metal-binding term; BuryP $=>$ penalty for buried polar groups; Rot $\mathrm{B}=>$ penalty for freezing rotatable bonds; Site $=>$ polar interactions at the active site; and the coefficients of vdW and Coul are: $\mathrm{a}=0.065$, $\mathrm{b}=0.130$

The generated poses were analyzed to observe their orientations and interactions.

Re-docking of co-crystallized ligands: To check the validity of the method, Eticlopride complexed with 3PBL was used and re-docked using the protocol described above for Glide docking. Each re-docked pose was evaluated by considering the RMSDs and docking scores. The selected re-docked pose was further evaluated by its interactions and energetic analysis to investigate the efficiency of the docking search algorithm and scoring function by comparing its values with the bound conformation.

\section{Results}

\section{Homology modelling}

Comparative modelling was used to model $\alpha 2$-adrenergic receptors of Human based on the X-Ray crystal structure of Human Dopamine D3 receptor (PDB ID: 3PBL) as they share highest sequence identity and transmembrane identity (a2a: 34\%, 49\%; a2b: 32\%, 49\%; a2c: $34 \%, 49 \%$ ), in comparison to available crystal structures (Table 1). The sequences of $\alpha 2$-ARs and the template 3PBL were aligned using Clustal $\mathrm{W}$ and then were manually adjusted to avoid insertions and deletions in the transmembrane domains. The transmembrane regions were aligned according to Baldwin's model for the alpha carbon positions in the transmembrane helices of the GPCR family [55]. In all three $\alpha 2$ ARs, the N, C-terminal part and the third intracellular loop (IL3), which is over 100 residues long, were not modelled because the available loop modelling algorithms are limited to up to 13 residues long loops [45].

The homology modelling package Modeller (version 9v8) [10] was used to generate the three-dimensional models for $\alpha 2$-ARs based on the $\mathrm{X}$-ray structure of Dopamine Receptor using the sequence alignment presented in Figure S1. The resulting models were first geometrically refined in order to reduce the side chain steric clashes. Later on, the entire receptor was energetically minimized using steepest descent method and conjugate gradient using CHARMm Force field. The final structures were validated using PSVS validation suite [48]. The final models have over $90 \%$ of residues in the favorable regions of the Ramachandran map (Figure S2) and all the main-chain parameters, like peptide bond planarity, bad nonbonded interactions, C- $\alpha$ distortion, overall G-factor, bond length distribution and side-chain parameters, are in the normal range.

Ramachandran Plot for a2a-AR showed $85.7 \%$ residues the most favored regions and $14.3 \%$ in the additionally allowed region. Verify $3 \mathrm{D}$ analysis showed a score of 0.21 , a Zscore of- 4.01 and the MolProbity Clash Zscore was-2.10.

Ramachandran Plot for $\alpha 2 \mathrm{~b}-\mathrm{AR}$ showed $85.2 \%$ residues the most favoured region, $14 \%$ in the additionally allowed region, $0.4 \%$ in the generously allowed region and $0.4 \%$ in the disallowed region. The Verify $3 \mathrm{D}$ score was 0.21 , the Zscore for this model was- 4.01 and the MolProbity Clash Zscore was-2.70.

Ramachandran Plot for $\alpha 2 \mathrm{c}$-AR showed $80.6 \%$ residues the most favoured region, $18.6 \%$ in the additionally allowed region and $0.8 \%$ in the generously allowed region. The Verify $3 \mathrm{D}$ scaore was 0.24 , the Zscore for this model was-3.53 and the MolProbity Clash Zscore was1.77

The Zscores for all three model structures are greater than-4, indicating that the structures are properly refined and can be used for further analysis.

\section{Binding site cavity analysis}

Binding site cavity volume was obtained by binding site cavity detection tool of DS 3.1. Our analysis showed largest binding cavity volume in $\alpha 2 b-A R\left(503 \AA^{3}\right)$, followed by a2c-AR $\left(471 \AA^{3}\right)$ and the smallest cavity was observed in a2a-AR $\left(403 \AA^{3}\right)$. The results are in agreement with previous studies, where the binding cavity predicted was largest for $a 2 b-A R$ [25].

\section{Docking results}

a2a-AR: Agonists: Of the docked agonists, the Dopamine was observed to have higher glide score $(-7.979107)$, followed closely by Adrenaline (-7.876917). The other agonists had a glide scores in the range-6.862784 to-4.244504. Dopamine was observed to interact through hydrogen bonding with the residues Asp 3.32 (TM3), Ser 5.46 (TM5) (Figure 3) and was also observed to interact through other electrostatic interactions with the residues Ser 5.42 (TM5), Tyr 7.43 (TM7). Some of the agonists such as Adrenaline and 2-amino-1phenylethanol were also involved in $\pi-\pi$ interactions with Phe 6.51 and Tyr 6.55. The details of the interactions of the other ligands are given in Supplementary table S1.

Antagonists: The ligand WB-4101 was observed to have higher bind affinity to a2a with a glide score of-9.093255, followed closely by OPC 28326, Spiroxatrine and Dibozane (Supplementary table S1). BRL44408, Chlorpromazine and Atipamezole showed hydrogen bonding with Asp 3.32. The residues Phe 6.51, Tyr 6.55, Phe 7.35, Tyr 3.28 were involved in $\pi-\pi$ interactions with the ligands (Supplementary table S1).

a2b-AR: Agonists: Guanfacine was observed to have the highest binding affinity with a glide score of-7.533895. The endogenous ligands Adrenaline and Dopamine followed closely with glide scores of-6.899865 and-6.858532 respectively. Most of the agonists were observed to interact with the $\alpha 2 \mathrm{~b}$ receptor through hydrogen bonding with Asp 3.32 (Supplementary table S1). Phe 6.51 and Tyr 6.55 were involved in $\pi-\pi$ interactions with some of the agonists (Supplementary table S1).

Antagonists: WB-4101 was found to have the highest glide score 
$(-8.641979)$ and was involved in interactions with Asp 3.32 (hydrogen bond), Lys xl2.51 ( $\pi$ - cation) and Phe $6.51(\pi-\pi)$. The other antagonists were observed to have a glide score in the range-8.592746 to-2.15852. Many of the antagonists were observed to be involved in interaction with the residue Asp 3.32 through hydrogen bond and with Phe 6.51 through $\pi-\pi$ interactions (Supplementary table S1).

a2c-AR: Agonists: Dopamine was found to have the highest binding affinity of the agonists used for docking in our study with a glide score of-9.078919 (Supplementary table S1). It was found to interact with the residue Asp 3.32 through Hydrogen bond formation (Figure 3). It was also involved in Hydrogen bonding with Ser 5.41 (Supplementary table S1). Most of the other agonists such as Adrenaline, 2-amino-1phenylethanol were also observed to interact with Asp D3.32 through hydrogen bonding and $\pi-\pi$ interactions with the residues Phe 6.51, Tyr 6.55, Phe 7.38 and Phe 7.39 (Supplementary table S1).

5.3.6) Antagonists: We observed that of the sixteen antagonists used for docking with a2c receptor, WB-4101 had the highest glide gscore (-9.87093) and showed $\pi-\pi$ with Phe 6.51 . The other antagonists were bound to the $\alpha 2 \mathrm{c}$ receptor with Glide scores in the range- 8.176154 to- 0.558762 (Supplementary table S1). The antagonists BRL-44408 and Atipamezole showed hydrogen bonding interaction with Asp 3.32 while Prazosin showed hydrogen bonding with Tyr 3.28 (Supplementary table S1). Most of the antagonists were involved in $\pi-\pi$ interactions with Phe 6.51, few with Phe 7.39 and Phe 5.48 (Supplementary table S1).

\section{The orientation of common residues in the models and the prediction of their importantance in residue ligand interactions}

Most of the residue, that were predicted facing the ligand binding cavity by earlier investigators, based on bovine Rhodopsin [22,25] and $\beta 2$-adrenergic receptor [44-47] models, were occupying the same position in the models based on human D3 Dopamine receptor also. The amino acid residues predicted to be the key determinants of agonist binding, D3.32, W6.48, S5.43 and S5.46, were well positioned to interact with the protonated nitrogen, aromatic ring, and catecholic hydroxyls of catecholamine agonists (Figure 3). The position of the binding site was comparable to what was observed by previous studies, which is a validation of experimental and theoretical findings by different groups $[18,21,22,25,44-47,54]$. Furthermore, as described before, the binding pockets were mainly formed by conserved hydrophobic amino acids of TM5 (F5.47) and TM6 (W6.48, F6.51, F6.52 and Y6.55). The aromatic rings of the hydrophobic side chains of these residues may interact with the aromatic rings (or other hydrophobic structures) of ligands through $\pi-\pi$ stacking interaction $[21,22,25]$. The binding modes of the ligands in our study (Figures 3 and 4) were generally consistent with previous results $[18,20-22,56-59]$ with some differences.However, the model based on the Human Dopamine D3 receptor (3PBL) was useful in identifying residues which may be important in conferring subtype specificity.

From our analysis of binding site residues, we observed that $\mathrm{V}$ (2.53) and V (2.57) were not facing ligand binding cavity and hence could not influence ligand binding as predicted [22]. F (3.35) [18,21,22] was projecting away from binding site and hence may not have any role in binding. This observation is in agreement with Frang et al. [60]. This group proved, by experimental studies, that $F$ (3.35) in a2a is not exposed in the binding pocket and thus not accessible for Phenoxybenzene and other receptor ligands. However, the orientation of C (3.36), important in ligand binding and earlier predicted by Frang et al. [60], was towards binding site proving its involvement in ligand binding. This observation supports experimental finding [60] and theoretical finding [22] hence proving that our models are suitable for further studies.

The other residues, $\mathrm{T}$ (3.37) [18,20-22] and I (3.40) [22], also may not be able to make any interaction as they are pointed downwards below the binding cavity. Nonetheless, we suggest that hydrogen bonding interaction between $\mathrm{S}$ (5.46) and $\mathrm{T}$ (3.37) along with van der Waals interaction with I (340), may be responsible for maintaining the receptor in inactive state as reported earlier [61] (Figure S3). We observed this interaction, in the receptor models of $\alpha 2 a, a 2 b$ and $\alpha 2 c$ adrenergic receptors (Figure S3). While in docked protein models, the distance between $S$ (5.46) and $T$ (3.37) and the orientation of the bonding residues were different, fitting well with the accepted mechanism of receptor activation [62]. Furthermore, we observed that the distance between T (3.37) and S (5.46) in a $2 \mathrm{a}$ is around $4.8 \AA$ and hence the hydrogen bonding interaction was impossible between these two residues, therefore less stability to an inactive state and thus can be easily activated. However, the functional relevance of this observation along with the cavity size, in the regulation of receptor needs further investigation. With a similar reasoning we propose that in $\alpha 2 c$, where the distance between S (5.56) and T (3.37) is $2.38 \AA$, the inactive state is more stabilized than $\alpha 2 \mathrm{a}$. However in $\alpha 2 \mathrm{~b}-\mathrm{AR}$ the distance between $\mathrm{T}$ (3.37) and S (5.46) is $1.9 \AA$ and hence the binding affinity is more, which results in the highly stabilized inactive state. Our results provide evidence of receptor activation, where it was suggested that $\mathrm{T}$ (3.37) interacts with TM5, stabilizing the inactive state of the receptor [61]. We would like to mention here that we observed inverse relationship between binding site cavity volume and stability of the inactive state of a2-AR as enforced by hydrogen bond formation, while I (3.40), highly conserved in the whole class A GPCR family, facilitates the reorientation of TM5. It was proposed that the structural change of TM5 during the process of GPCR activation involves a local $\mathrm{P}(5.50)$ induced unwinding of the helix, acting as a hinge, and the highly conserved hydrophobic I (3.40) side chain, acting as a Pivot [61]. We also agree that I (3.40) (Figure S3) is not involved in the initial binding step but participates in the subsequent signal propagation as was observed in mutational analysis of I (3.40) in Histamine $\mathrm{H} 1$ receptor upon histamine binding [61]. The difference in the orientation of the residues, namely $\mathrm{T}$ (3.37) and S (5.46), before and after activation supports the findings of Sansuk et al. [61] that there is a minor, but significant, clockwise rotation of TM3 during the process of receptor activation.

The cationic nitrogen present in agonists formed a salt bridge with negatively charged side chain of carboxylate of D (3.32) in a2ARs (Figure 3). Agonists were docked close to S (5.42) and S (5.46), the residues predicted to be important for ligand binding [18,20-22]. However, not all of the antagonist docking modes formed the required interaction with D (3.32), and many were shifted away or remained at the top of the binding cavity as reported earlier [22,46]. We relate this docking mode to the residues $\mathrm{T}$ (3.37) and $\mathrm{S}$ (5.46) which are responsible for the rotation of TM3 in conjunction with I (3.40) with $\mathrm{P}$ (5.50) at pivot [61]. This rotation of TM3 may create new space near TM2/TM7 such that antagonists would be shifted away from TM5. Moreover, the absence of interaction of $\mathrm{D}$ (3.32) with antagonist may be due to alternate binding mode, where in the antagonists interact with D (3.32) via carboxylate-aromatic interactions as reported earlier [22]. The position of S (5.46), which was predicted to be important for binding, appears to be away from ligand binding cavity and would not 

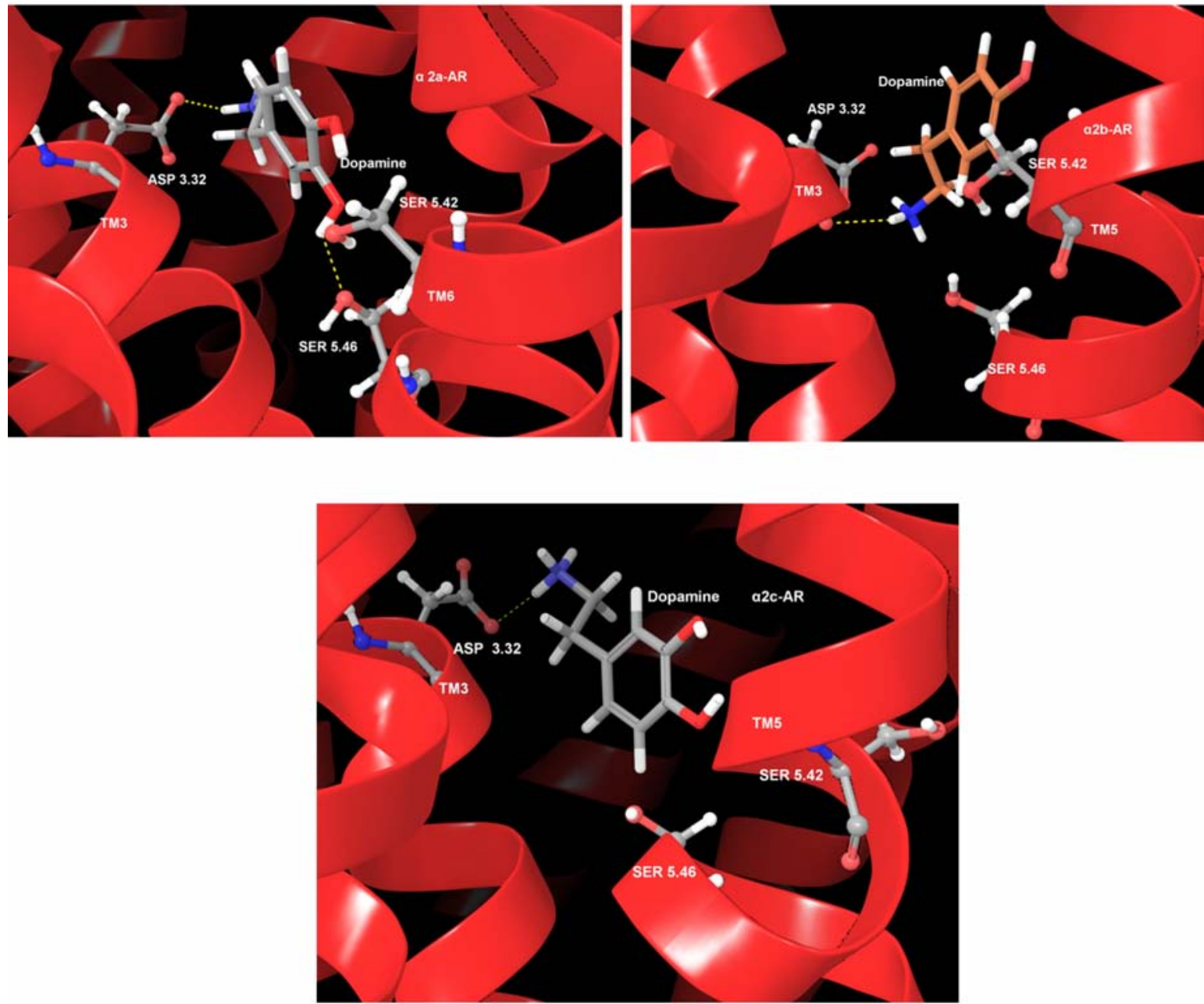

Figure 3: Best Docked confirmation of Dopamine and key residues with a2a-, a2b- and a2c- ARs. Structural models for the human a2- adrenoceptors were constructed based on homology with Human dopamine D3 structure (see Methods). Dopamine was positioned based on key amino-acid contacts identified in Peltonen et al. (2004) $\mathrm{D}(3.32), \mathrm{S}(5.46)$ and $\mathrm{S}(5.42)$

be able to form any interaction with ligands but may play important role in receptor activation [61]. F (5.47) was also unable to form any interaction with ligand as predicted before $[18,20,22]$. We believe that stronger interactions with D (3.32) and W (6.48) occur in a2-ARs and the hydrogen bonding network is different in a2-ARs. We propose the interaction D (3.32) or/and W (6.48) may be the original driving force during the whole activation process similar to the observation made by Gong and Wang [63].

$\mathrm{F}(6.51)[18,20-22]$ appeared to interact while $\mathrm{F}(6.52)[18,20,22]$ and $\mathrm{F}$ (6.53) (Figure S4) [21] were not interacting at all in $\alpha 2 \mathrm{a} / \mathrm{b} / \mathrm{c}-\mathrm{AR}$. W (6.48) was oriented in similar position but was pointed towards ligands and may play key role in activation even though no hydrogen bonding was visible in the models. On binding, the aromatic catechol ring of catecholamines presumably has a direct interaction with the aromatic residues of the rotamer toggle switch, $\mathrm{W}$ (6.48) and F (6.52). Previous studies using Monte Carlo simulations suggested that rotamer configurations of $\mathrm{C}$ (6.47), $\mathrm{W}(6.48)$ and $\mathrm{F}$ (6.52), the residues that comprise the rotamer toggle switch, were involved in the movement of the cytoplasmic end of the TM6 by coupling and modulating around highly conserved Proline kink (6.50) [64]. The next residue predicted earlier was F (7.38) [18,20] but it was pointing away from ligand binding cavity in our models and hence was unable to interact with ligands in $\alpha 2 \mathrm{a} / \mathrm{b} / \mathrm{c}$-ARs. This observation is in agreement with the findings of Balogh et al. [25].

\section{Residues which may play important role in subtype specificity}

Recently, Ostopovici-Halip et al. [45] have analyzed the role of different amino acids occupying the same position around the endogenous ligand within $6 \AA$ distance and gave a detailed explanation of the variations and their role in the binding of subtype specific ligands. Our findings were in agreement with their analysis to some extent and differed with them on the role of some residue variation in giving subtype specificity. Apart from this we have been able to identify novel residues which may be important for subtype specificity.

Our models also depict that the variation at positions 2.57 (Val86/ Ile65/Val104) and 5.39 (Val197/ Ile173/ Ile211) in $\alpha 2 \mathrm{a}, \alpha 2 \mathrm{~b}$ and $\alpha 2 \mathrm{c}$, would not make a big difference in the properties of the binding site as explained by earlier investigators $[45,46]$. We agree with the earlier studies in terms of the similarity and differences shared by valine and isoleucine with regard to topology, physicochemical properties, size 


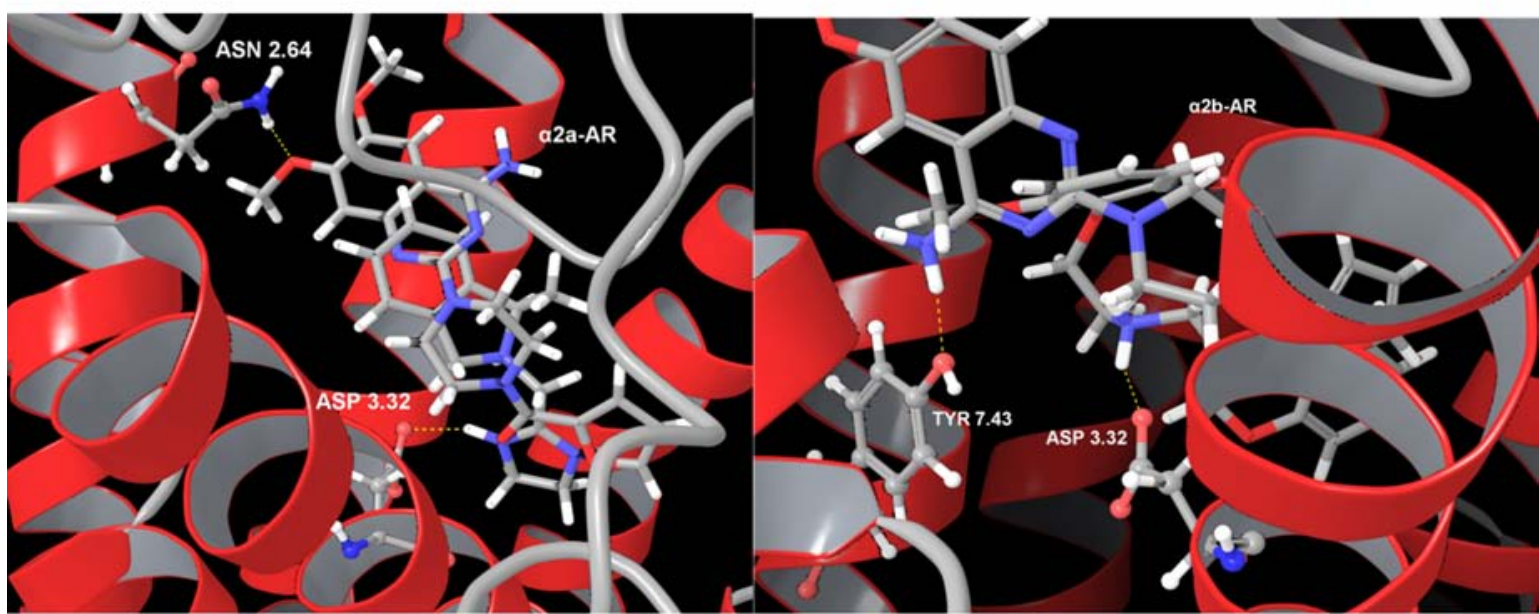

a

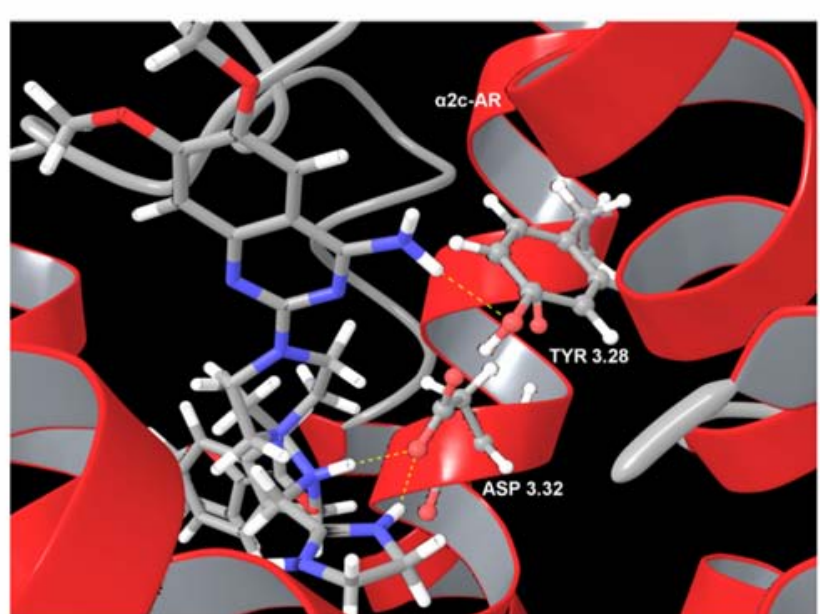

b

C

Figure 4: a2-ARs with docked antagonist. a) a2a-AR. b) a2b-AR. c) a2c-AR. Structural models for the human $\alpha 2-$ adrenoceptors were constructed based on homology with Human dopamine D3 structure (see Methods).

and volume. Though the presence of valine residue would allow for ligands with larger substituent, ligands that can distinguish between the two residues are thought to be rare [45,46]. However, the orientation of residue V/I (5.39) in a2a-AR and 2b-AR was towards center of binding cavity whereas the I (5.39) in $\alpha 2 \mathrm{c}$ was facing outside the binding cavity in our models, which can play key role in subtype specificity. This observation disagrees with Laurila et al. [46] and Ostopovici-Halip et al. [45], who have predicted that this change may not make a difference in binding properties.

From analysis of our models, we observed that Y (5.38) [43] was positioned between TM5 and TM4 in $\alpha 2 \mathrm{a}$ and $\alpha 2 \mathrm{~b}$ whereas it is positioned within the binding cavity in $\alpha 2 \mathrm{c}$. Even though its role in ligand binding was predicted earlier, its role in subtype specificity was not suggested before. We propose that the orientation of this residue should be considered in designing subtype specific drugs (Figure S5).

The next residue which may contribute to subtype specificity is $\mathrm{C}$ (5.43)/S (5.43)/C (5.43) [45]. Our models show that the cysteine (5.43) in $a 2 \mathrm{a}$ and $2 \mathrm{c}$ would not interact with the ligands but $S(5.43)$ in $\alpha 2 \mathrm{~b}$ is close to ligand binding site. The hydroxyl group in the serine sidechain could be involved in the formation of hydrogen bonds with the protein backbone or with diverse polar functional groups from ligands (Figure S6), confirming earlier observation of Ostopovici-Halip et al. [45]. The orientation of S (5.43) and its position, close to agonist, in our models also confirms the findings of Balogh et al. [25]. As described by Ostopovici-Halip et al. [45], due to its position C (5.43) in a2a-AR and $\alpha 2 \mathrm{c}-\mathrm{AR}$, cannot engage in disulfide bond formation with the other cysteines. Thus, this residue confers subtype selectivity which can be exploited during ligand design through incorporation of a substituent that can interact with the side chain of S (5.43) for a2b-AR and C (5.43) for $a 2 a-A R$ and $a 2 c-A R$. Balogh et al. [25] also reported the role of this residue in conferring subtype selectivity during agonist binding.

The binding site residues in $\mathrm{xl} 2$ loop at the top of binding cavity, which we predict could give rise to subtype specificity, are E (xl2.51)/K (xl2.51)/G (xl2.51). Thompson et al. [47] and Laurila et al. [59] have reported that this residue along with $\mathrm{xl} 2.50$ and $\mathrm{xl} 2.52$ acts as a lid covering the binding cavity and may interact with certain ligands to influence the binding mode. Our models show that the position of lysine in $\alpha 2 \mathrm{~b}-\mathrm{AR}(\mathrm{K}(\mathrm{xl} 2.51))$ was at the top of binding cavity, going across the cavity. $\mathrm{N}(\mathrm{xl} 2.53)$ appears to be the major player along with $\mathrm{E}(\mathrm{xl} 2.51) / \mathrm{K}(\mathrm{xl} 2.51) / \mathrm{G}(\mathrm{xl} 2.51)$ influencing ligand entry (Figure 5). 

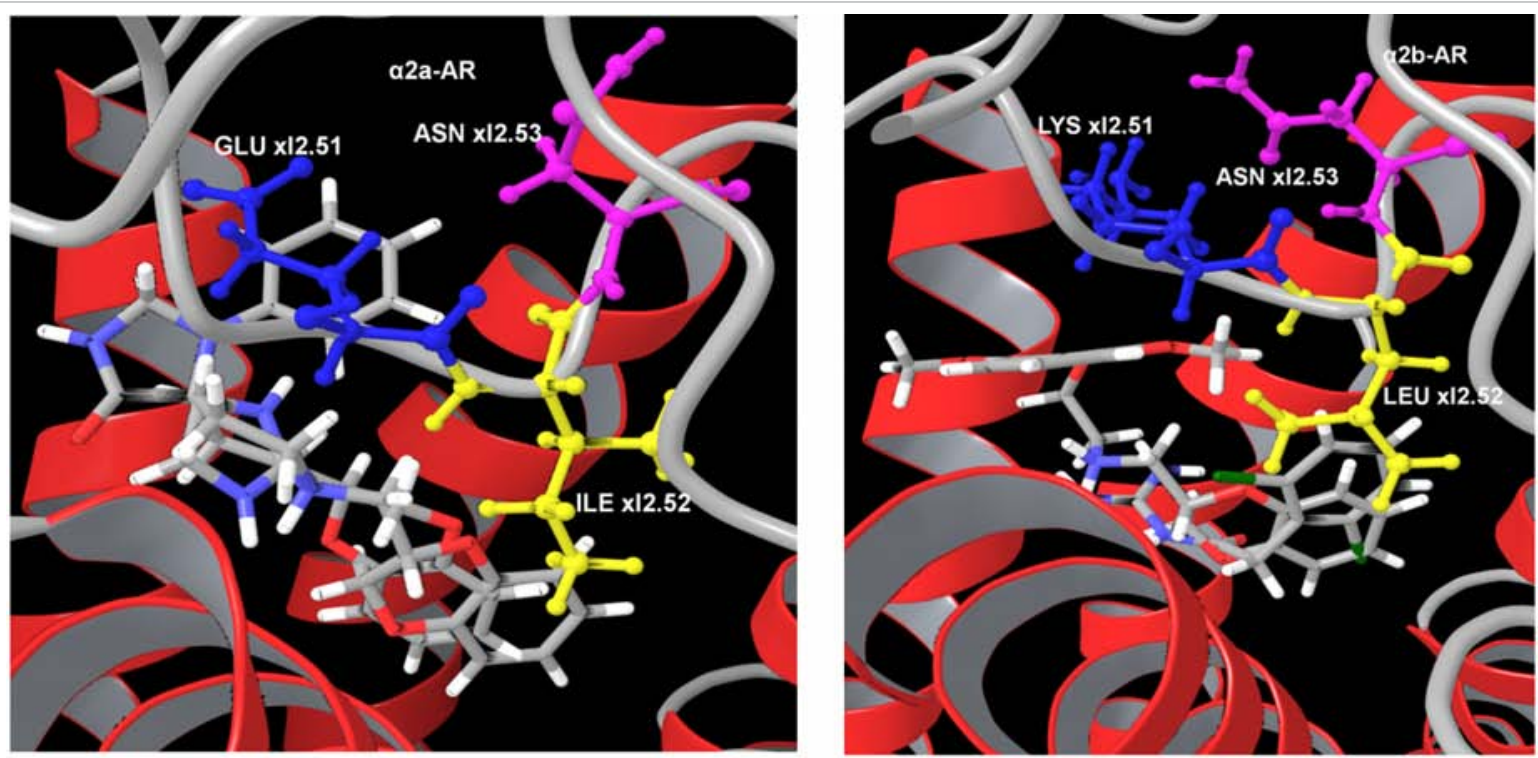

a

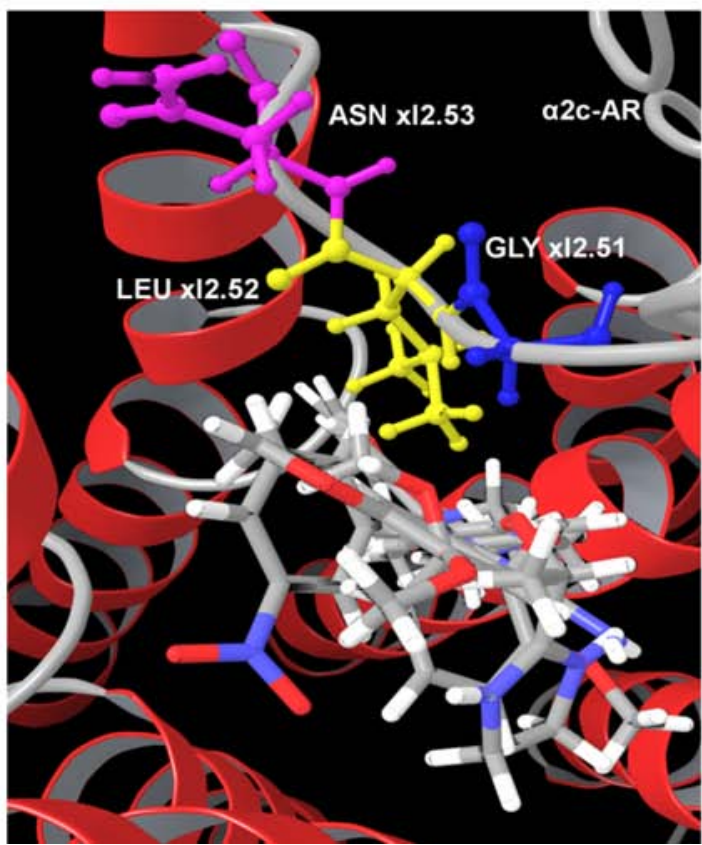

b

C

Figure 5: Residue position at 2.51: a) Orientation of $E(x \mid 2.51), I(x \mid 2.52)$ and $N(x \mid 2.53)$ on the top of binding cavity in $\alpha-2 a$ b) Orientation of $K(x \mid 2.51), L(x \mid 2.52)$ and $N$ (x|2.53) on the top of binding cavity in $\alpha-2 b c)$ Orientation of $G(x \mid 2.51), L(x \mid 2.52)$ and $N(x \mid 2.53)$ on the top of binding cavity in a2c-AR.

The variations in $\mathrm{xl} 2$, described by previous investigators, which could give rise to subtype specificity, were K174/D153/R192 (xl2), I190/L166/ L204 (xl2.52), and D192/Q168/ D206 (xl2.55) in a2a-AR, a2b-AR and a2c-AR respectively [45]. Our models show that the orientation of K174/D153/R192 (xl2) and D1192/Q168/D206 (xl2.55) (Figures 6b, $6 \mathrm{c}$ and $6 \mathrm{~d})$ were pointed upwards and hence may not interact with ligands directly but may play role in the entry of ligand as they are close to binding site cavity, and interaction with legends before they enter binding cavity would play crucial role in ligand recognition specific to subtype $\alpha 2 \mathrm{a}$ and signalling ability of a ligand [65]. However, the other residue at position xl2.52, (I190/L166/L204) pointed downwards, may give rise to subtype specific binding as suggested by Ostopovici-Halip et al. [45] (Figures 6b, 6c, 6d). As stated by Ostopovici-Halip et al. [45], the negatively charged carboxyl side chain of Asp192 (a2a-AR) and Asp 206 ( $\alpha 2 c-A R)$ and the polar side chain of Gln 168 ( $\alpha 2 b-A R)$ could be used in designing ligands with substituent of opposite charge that can interact with these residue side chains. We suggest that the prolines may have important role in giving structural stability to secondary structural elements. Thus, we propose that mutation of proline at (xl2.48) may alter loop architecture of $\mathrm{xl} 2$ and may alter ligand binding affinity of subtype $b$. Recently, single proline was reported to be associated with some architectural pattern rather than longer prolines [66].

The cysteine at position $(\mathrm{xl} 2.50)$ has similar roles in the $\beta_{2}$ adrenoceptor and in rhodopsin, forming a disulphide bond with the cysteine at position 3.25 in TM3 and constraining xl2, to fold on top of the binding cavity. The other disulphide bridge was observed 

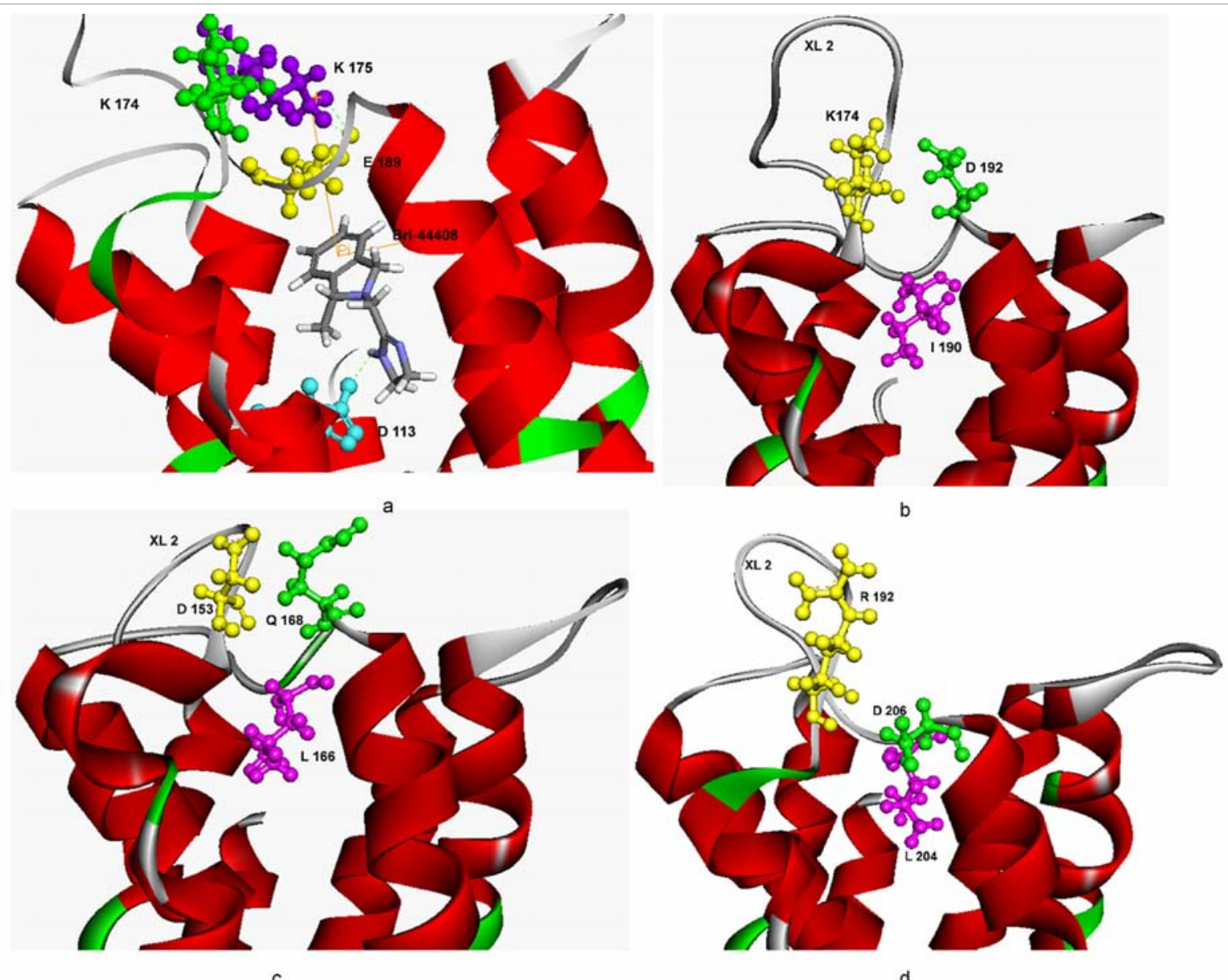

Figure 6: a) Docking pose with BRL-44408 with a-2a AR. b) The orientation of K174/D153/R192 in a2a-AR. c) D192/Q168/D206 in a2b-AR d) I109/L166/L204 in a2cAR.

between cysteines in $\mathrm{xl} 3$ region only in $\mathrm{a} 2 \mathrm{~b}(397-401)$ and $a 2 \mathrm{c}(408$ 412) adrenergic receptors. In $a 2 \mathrm{a}$ one of the cysteine residues in $\mathrm{xl} 3$ was replaced by glycine and hence disulphide bridge could not be established. We relate substitution of cysteine by glycine in Human a2a receptor a process of creating specificity to receptor, thus giving more space for the entry of ligands. The functional correlation of this structural feature needs further evaluation.

From our modelling and docking studies we show that residue variation at R405/H404/G416 (7.32), present in the beginning of seventh helix, would play key role in subtype specificity. $\mathrm{R}$ (7.32) in a2a-AR was observed to interact with antagonist docked in the top of binding cavity through hydrogen bond formation as it is positioned close to TM7 (Figure S7). Thus, we believe that R (7.32) could be related to subtype specificity of a2a-AR.. Earlier, Laurila et al. [59] have also suggested that R7.32 could indirectly influence ligand binding through interaction with xl2. Bokoch et al. [67] reported that a salt bridge is formed between Lys305 (7.32) and Asp 192 (xl2) in $\beta 2$-adrenoceptor and this bridge is displaced by TM6 during activation of the receptor.

Ostopovici-Halip et al. [45], in their molecular docking experiments with JP-1302, a selective antagonist of the a2c-AR, have mentioned that presence of glycine (7.32) in a2c-AR subtype allows for the accommodation of the ligand's acridine ring into a hydrophobic pocket located in the extracellular part of the receptor, between the upper parts of helices 6 and 7. This position is occupied by larger residues-arginine, in the case of $\alpha 2 \mathrm{a}-\mathrm{AR}$ and histidine in the case of $\alpha 2 \mathrm{~b}-\mathrm{AR}$, which obstruct the acridine ring, and implicitly the entire ligand, to adopt a similar orientation as in the $\alpha 2 \mathrm{c}-\mathrm{AR}$ binding site.

The next residue which was identified from molecular models based on Human dopamine D3 with D2/D3 antagonist was F (7.39). Even though its role in ligand binding was predicted earlier [18,20-22], our models show that its position within the binding cavity may determine the binding cavity volume of the associated subtype. The orientation of this residue is same in $\alpha 2 \mathrm{a}$ and $\alpha 2 \mathrm{c}$ while in $\alpha 2 \mathrm{~b}$ it is pointed towards the membrane (Figure S8).

G (7.42), predicted by Gentili et al. [21], showed no interaction with ligands in all the a2-AR. However, the orientation of G (7.42) was towards ligand binding cavity in $\mathrm{a} 2 \mathrm{a}-\mathrm{AR}$ and outside in $\mathrm{a} 2 \mathrm{~b}$ and $2 \mathrm{c}$ (Figure S4). Following residue was Y (7.43), which was penetrated deep into the ligand binding cavity and was in close contact with the ligands even though no hydrogen bonds were seen. Tyrosine at this position may interact with aromatic rings of ligands through $\pi-\pi$ stacking interactions as reported by Gentili et al. [21] and Xhaard et al. [22]

\section{Docking studies with subtype specific ligands}

We docked subtype specific drug BRL-44408, with the models of a2-ARs. BRL-44408 docking was reported earlier in the model based 
on $\beta 2$ adrenergic receptor [45]. BRL-44408 is stabilized by cation- $\pi$ interactions with $\mathrm{K}(175)(\mathrm{xl} 2)$, whereas, $\mathrm{K} 175$ is stabilized by hydrogen bond with E (189) (xl2) (Figure 6a). The residues identified for binding of BRL-44408 by earlier study [45], K174/ D153/ R192 (xl2), are present on the top of binding cavity of the models and may not play any role in ligand binding directly, but interactions between K174/D192/I109 (xl2) in $\alpha 2 a, D 153 / Q 168 / L 166$ (xl2) in a2b and R192/D206/L204 (xl2) in a2c can be attributed to creating subtype specificity as their interactions may enclose a characteristic space. The specificity of BRL- 44408 was further confirmed by higher glide score for a2a-AR (Table S1). A more negative value indicates a more favorable binding. Glide score is an empirical scoring function that approximates the ligand binding free energy. It has many terms, including force field (electrostatic, van der Waals) contributions and terms rewarding or penalizing interactions known to influence ligand binding. It has been optimized for docking accuracy, database enrichment, and binding affinity prediction $[54,68,69]$. Docking of a2c-receptor with JP-1302 resulted in higher glide score for $\alpha 2 c-A R$ compared to $\alpha 2 a-A R$ and $\alpha 2 b-A R$ (Figure 7 ) in agreement with Ostopovici et al. 44] but we suggest that the residue F (7.35) involved in $\pi-\pi$ stacking interactions may stabilize the ligands [22] and these interactions may be influenced by the side chains of the residue $\mathrm{R} / \mathrm{H} / \mathrm{G}$ at 7.32 giving subtype specificity to JP-1302. We have identified $\mathrm{F}$ (7.35) to be important in ligand binding in our previous paper [69]. However, the amino acid residue variation described by Ostopovici-Halip et al. [45] indicated for subtype specificity, was not consistent with our observation from our models. We suggest that the orientation of T/G/Y (6.58) and K/Q/K (7.36) may not play important role in giving rise to subtype specificity to antagonist as they are pointed away from the docked position of the ligand.

The method of docking (Glide) was tested by docking eticlopride (antagonist) to crystal structure of Human dopamine D3 Receptor. The results obtained reproduced the interactions reported in the original study by Chien et al. [31].

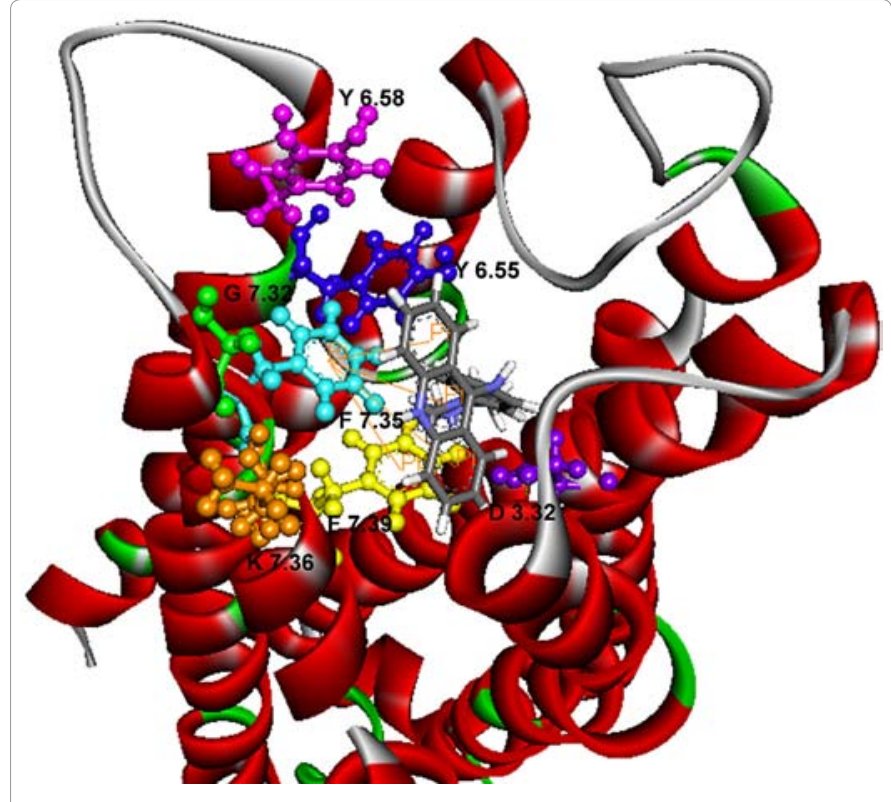

Figure 7: Docking of $\alpha 2 \mathrm{c}$ receptor with JP-1302.

\section{Discussion}

GPCR crystallization is a challenging task by itself as they are unstable outside the membrane and adopt many conformational states and besides all this, loops add to the structural diversity. The fact that they are involved in many physiological processes, make them important targets in GPCR superfamily of proteins $[1,70]$. However, the absence of high resolution crystal structure of a2-AR subtypes is a limitation in understanding atomic details. We have modelled a2-adrenergic receptor subtypes using Human Dopamine D3 receptor (3PBL) as template. Our models reproduced most of the key interactions reported by experimental and theoretical investigators $[18,20-22,58,59]$ with some novel findings.

The first important finding was with respect to binding site cavity volume. While the binding site volume in our models was largest in $\mathrm{a} 2 \mathrm{~b}-\mathrm{AR}$, as predicted by previous studies based on the crystal structure of Rhodopsin and $\beta 2$ adrenergic receptor, the smallest cavity was observed in $\alpha 2 \mathrm{a}-\mathrm{AR}$, instead of $\alpha 2 \mathrm{c}-\mathrm{AR}$, as reported by previous results. Another important observation was comparable binding site volume of $a 2 b-$ and $2 c-A R$. This observation can be correlated to the shared specificity of ligands between $\alpha 2 b$ and $\alpha 2 c$ subtype. We propose that small binding site cavity volume could be the reason for the observed 10-100 fold lower affinity binding of bulky antagonist with an extended side chain to $\alpha 2 \mathrm{a}$ in comparison to $\mathrm{a} 2 \mathrm{~b}$ and $\mathrm{a} 2 \mathrm{c}$. This experimental observation could not be explained by studies based on previous models which concentrated on differences in TM5 and $\mathrm{xl} 2$ and involvement of TM1 [45]. From our analysis of binding cavity residues it was observed that, the models agree that residues D (3.32), C (3.36), S(5.42), S (5.46), $\mathrm{F}$ (6.51), W (6.48), Y (7.43), F(7.38) and disagree that the residues $\mathrm{V}$ (2.53), V (2.57), F (3.35), T (3.37), I (3.40), S (5.46), F (5.47), F (6.52) are exposed to binding cavity.

The next important result from our studies was the finding that the residues $\mathrm{T}$ (3.37) [18,20-22] and I (3.40) [22] may not be able to participate in ligand binding as predicted by previous investigators. We believe that interaction between $\mathrm{T}$ (3.37) and S (5.46) may play an important role in inactive state stabilization along with I (3.40) in signal propagation [59]. We extended our study to analyze the residues predicted to play a role in subtype specificity. Here, our models support the findings of Xhaard et al. [22] and Ostopovici-Halip et al. [45] that variation in position 2.57 (Vl86/I65/V104), 5.39 (V197/ I173/ I211), xl2.52 (I190/L166/L204) would not affect the properties of binding sites. Our models also support earlier findings that the residue at position 5.43, C(5.43)/S(5.43)/C(5.43), could be considered for subtype specificity as described by Ostopovici-Halip et al [45].

From our modelling studies we have observed that the residues $\mathrm{E}$ $(\mathrm{xl} 2.51) / \mathrm{K}(\mathrm{xl} 2.51) / \mathrm{G}(\mathrm{xl} 2.51)$ and $\mathrm{N}(\mathrm{xl} 2.53)$ together play key role in subtype specificity, as their interactions would influence the available space for ligand binding. Mutational analysis of $\mathrm{N}$ (xl2.53) will elucidate the role of these residues in subtype specificity. The length and the charge of Lysine may influence the ligand entry and hence create specificity for a2b-subtype. Hydrogen bonding interactions in $\mathrm{xl} 2$ may play important role in stabilizing $\mathrm{xl} 2$ loop and influence the affinity of ligand binding by acting as important constraint, thereby limiting the availability of binding cavity for ligand binding.

In our models also such interaction between K(175)-E189 (xl2.51) in $a 2 a-A R$ and between Q (193)-Q201(xl2.54) in a2c and between $\mathrm{Q}(154)-\mathrm{K} 165$ (xl2.51) in a2b-AR was observed (Figure S9). It was observed that the hydrogen bond formed between Q154-K165 (xl2.51) 
in $\alpha 2 b$ was missing after docking. The functional relevance of this change needs to be correlated further but this interaction appears to play important role between active and inactive state. Studies on GPCRs have indicated the functional roles of loops in receptor activation and ligand binding [71]. The second extracellular loop was reported to be important in ligand selectivity in aminergic and other small moleculebinding GPCRs as described in a review [72]. We propose that mutation of proline at (xl2.48) may alter loop architecture of xl2 and may alter ligand binding affinity of subtype $\mathrm{b}$. Constraining the loop seems to be essential for receptor activation among all class-A GPCRs because disturbance of the conserved disulfide bridge between xl2 and TM3 largely diminishes receptor function [73]. As stated earlier, $\mathrm{xl} 2$ is an important determinant in the subtype selectivity of ligands. The conformation that $\mathrm{xl} 2$ can adopt to accommodate these large side chains might be receptor-specific and could be used in the design of subtype-selective ligands [72].

R405/H404/G416 (7.32) is present in the beginning of seventh helix. We have observed that variation at 7.32 may interfere with interaction between ligands and F (3.35) and this interaction was identified by our modelling studies. F (3.35) was identified to stabilize ligands with $\pi-\pi$ stacking interactions in docking of JP-1302, an a $2 \mathrm{c}$ specific antagonist. Our models have also shown that R (7.32) could make specific interactions with antagonist at the top of binding cavity in $\alpha 2 a-A R$ as reported earlier [46].

Our models have identified the key interactions of BRL-44408, an a2a specific antagonist with K 175 (xl2). Furthermore, we believe that these interactions are stabilized with the formation of hydrogen bond with E189. Further analysis of K175 (xl2) and E189 (xl2) is required for understanding its role in subtype specificity.

The third extracellular loop has been proposed to be important in GPCR signaling [74]. In Human a2a-AR one of the cysteine residues in $\mathrm{xl} 3$ was replaced by glycine and hence disulfide bridge could not be established. We relate substitution of cysteine by glycine in a $2 \mathrm{a}-\mathrm{AR}$ receptor a part of creating specificity to receptor, thus giving more space for the entry of ligands. The functional correlation of this structural feature needs further evaluation. However, there are evidences based on mutagenesis studies, in which extracellular non conserved cysteine molecules were predicted to be important for other aspects like kinetics of ligand binding [75].

We believe that comparable size of the binding cavity of $a 2 b-A R$ $\left(503 \AA^{3}\right)$ and $\alpha 2 c$ - AR $\left(471 \AA^{3}\right)$ is one of the factors influencing the similar binding affinity of ligands studied. The funnel shaped geometry of binding cavity was observed as observed by Balogh et al. [25].

\section{Conclusion}

Thus, in our study, we obtained Human alpha2-adrenergic receptors ( $\alpha 2 a, \alpha 2 b$ and $\alpha 2 c$ ) homology models, based on crystal structure of Human Dopamine D3 receptor as it showed highest transmembrane identity in comparison to available crystal structures. We suggest that these models would prove useful in structure based drug design studies, as they agreed with experimental findings regarding the role of residues important for binding and showed correct orientation of the conserved residues involved in binding as reported before. Based on this, we suggest that the predictions for the residues critical for subtype specificity may be important.

\section{References}

1. Bylund DB, Eikenberg DC, Hieble JP, Langer SZ, Lefkowitz RJ, et al. (1994)
International Union of Pharmacology nomenclature of adrenoceptors. Pharmacol Rev 46: 121-136.

2. IUPHAR Database, Intenational Union of Basic and Clinical Pharmacology.

3. Saunders C, Limbird LE (1999) Localization and trafficking of alpha2-adrenergic receptor subtypes in cells and tissues. Pharmacol Ther 84: 193-205.

4. Kable JW, Murrin LC, Bylund DB (2000) In vivo gene modification elucidates subtype-specific functions of alpha(2)-adrenergic receptors. J Pharmacol Exp Ther 293: 1-7.

5. Brede M, Nagy G, Philipp M, Sorensen JB, Lohse MJ, et al. (2003) Differential control of adrenal and sympathetic catecholamine release by alpha 2-adrenoceptor subtypes. Mol Endocrinol 17: 1640-1646.

6. Philipp M, Brede M, Hein L (2002) Physiological significance of alpha(2)adrenergic receptor subtype diversity: one receptor is not enough. Am J Physio Regul Integr Comp Physiol 283: R287-R295.

7. Ruffolo RR Jr, Hieble JP (1994) Alpha-adrenoceptors. Pharmacol Ther 61 1-64.

8. MacDonald E, Kobilka BK, Scheinin M (1997) Gene targeting--homing in on alpha 2-adrenoceptor-subtype function. Trends Pharmacol Sci 18: 211-219.

9. Scholz J, Tonner PH (2000) Alpha2-adrenoceptor agonists in anaesthesia: a new paradigm. Curr Opin Anaesthesiol 13: 437-442.

10. Sali A, Blundell TL (1993) Comparative protein modelling by satisfaction of spatial restraints. J Mol Biol 234: 779-815.

11. Cavasotto CN, Phatak SS (2009) Homology modeling in drug discovery: current trends and applications. Drug Discov Today 14: 676-683.

12. Costanzi S (2012) Homology modeling of class a G protein-coupled receptors Methods Mol Biol 857: 259-279.

13. Worth CL, Kreuchwig A, Kleinau G, Krause G (2011) GPCR-SSFE: a comprehensive database of $\mathrm{G}$-protein-coupled receptor template predictions and homology models. BMC Bioinformatics 12: 185.

14. Carlsson J, Coleman RG, Setola V, Irwin JJ, Fan H, et al. (2011) Ligand discovery from a dopamine D3 receptor homology model and crystal structure. Nat Chem Biol 7: 769-778.

15. Schertler GF, Villa C, Henderson R (1993) Projection structure of rhodopsin Nature 362: 770-772.

16. (2000) Crystal structure of rhodopsin: a G protein-coupled receptor. Palczewsk $\mathrm{K}$, ${ }^{*}(1)$ kumasaka $\mathrm{T}$, hori $\mathrm{T}$, behnke $\mathrm{CA}$, motoshima $\mathrm{H}$, fox BA, trong IL, teller DC, okada T, stenkamp RE, yamamoto M, miyano M. Science 2000;289:739745 Am J Ophthalmol 130: 865

17. Okada T, Sugihara M, Bondar AN, Elstner M, Entel P, et al. (2004) The retina conformation and its environment in rhodopsin in light of a new 2.2 A crystal structure. J Mol Biol 342: 571-583.

18. Nyrönen T, Pihlavisto M, Peltonen JM, Hoffrén AM, Varis M, et al. (2001) Molecular mechanism for agonist-promoted alpha(2A)-adrenoceptor activation by norepinephrine and epinephrine. Mol Pharmacol 59: 1343-1354.

19. Teller DC, Okada T, Behnke CA, Palczewski K, Stenkamp RE (2001) Advances in determination of a high-resolution three-dimensional structure of rhodopsin, a model of G-protein-coupled receptors (GPCRs). Biochemistry 40: 7761-7772.

20. Peltonen JM, Nyrönen T, Wurster S, Pihlavisto M, Hoffrén AM, et al. (2003) Molecular mechanisms of ligand-receptor interactions in transmembrane domain $\mathrm{V}$ of the alpha2A-adrenoceptor. Br J Pharmacol 140: 347-358.

21. Gentili F, Ghelfi F, Giannella M, Piergentili A, Pigini M, et al. (2004) alpha 2-adrenoreceptors profile modulation. 2. Biphenyline analogues as tools for selective activation of the alpha 2C-subtype. J Med Chem 47: 6160-6173.

22. Xhaard $\mathrm{H}$, Nyrönen $T$, Rantanen $\mathrm{VV}$, Ruuskanen JO, Laurila J, et al. (2005) Model structures of alpha-2 adrenoceptors in complex with automatically docked antagonist ligands raise the possibility of interactions dissimilar from agonist ligands. J Struct Biol 150: 126-143.

23. Balogh B, Hetényi C, Keseru MG, Mátyus $P$ (2007) Structure-based calculation of binding affinities of alpha $2 \mathrm{~A}$-adrenoceptor agonists. ChemMedChem 2: 801 805

24. Carrieri A, Fano A (2007) The in silico insights of alpha-adrenergic receptors over the last decade: methodological approaches and structural features of the 3D models. Curr Top Med Chem 7: 195-205. 
Citation: Jayaraman A, Jamil K, Kakarala KK (2013) Homology Modelling and Docking Studies of Human $\alpha 2$-Adrenergic Receptor Subtypes. J Comput Sci Syst Biol 6: 136-149. doi:10.4172/jcsb.1000111

25. Balogh B, Szilágyi A, Gyires K, Bylund DB, Mátyus P (2009) Molecular modelling of subtypes (alpha(2A), alpha(2B) and alpha(2C)) of alpha(2)-adrenoceptors: a comparative study. Neurochem Int 55: 355-361.

26. Cherezov V, Rosenbaum DM, Hanson MA, Rasmussen SG, Thian FS, et al. (2007) High-resolution crystal structure of an engineered human beta2adrenergic $G$ protein-coupled receptor. Science 318: 1258-1265.

27. Warne T, Serrano-Vega MJ, Baker JG, Moukhametzianov R, Edwards PC, et al. (2008) Structure of a beta1-adrenergic G-protein-coupled receptor. Nature 454: 486-491.

28. Murakami M, Kouyama T (2008) Crystal structure of squid rhodopsin. Nature 453: 363-367.

29. Jaakola VP, Griffith MT, Hanson MA, Cherezov V, Chien EY, et al. (2008) The 2.6 angstrom crystal structure of a human A2A adenosine receptor bound to an antagonist. Science 322: 1211-1217.

30. Wu B, Chien EY, Mol CD, Fenalti G, Liu W, et al. (2010) Structures of the CXCR4 chemokine GPCR with small-molecule and cyclic peptide antagonists. Science 330: 1066-1071.

31. Chien EY, Liu W, Zhao Q, Katritch V, Han GW, et al. (2010) Structure of the human dopamine D3 receptor in complex with a D2/D3 selective antagonist. Science 330: 1091-1095.

32. Shimamura T, Shiroishi M, Weyand S, Tsujimoto H, Winter G, et al. (2011) Structure of the human histamine $\mathrm{H} 1$ receptor complex with doxepin. Nature 475: 65-70.

33. Kruse AC, Hu J, Pan AC, Arlow DH, Rosenbaum DM, et al. (2012) Structure and dynamics of the M3 muscarinic acetylcholine receptor. Nature 482: 552556 .

34. Manglik A, Kruse AC, Kobilka TS, Thian FS, Mathiesen JM, et al. (2012) Crysta structure of the $\mu$-opioid receptor bound to a morphinan antagonist. Nature 485: 321-326.

35. Hanson MA, Roth CB, Jo E, Griffith MT, Scott FL, et al. (2012) Crystal structure of a lipid G protein-coupled receptor. Science 335: 851-855.

36. Haga K, Kruse AC, Asada H, Yurugi-Kobayashi T, Shiroishi M, et al. (2012) Structure of the human M2 muscarinic acetylcholine receptor bound to an antagonist. Nature 482: 547-551.

37. Wu H, Wacker D, Mileni M, Katritch V, Han GW, et al. (2012) Structure of the human I̊$^{\circ}$-opioid receptor in complex with JDTic. Nature 485: 327-332.

38. Granier S, Manglik A, Kruse AC, Kobilka TS, Thian FS, et al. (2012) Structure of the $\delta$-opioid receptor bound to naltrindole. Nature 485:400-404.

39. White JF, Noinaj N, Shibata Y, Love J, Kloss B, et al. (2012) Structure of the agonist-bound neurotensin receptor. Nature 490: 508-513.

40. Park SH, Das BB, Casagrande F, Tian Y, Nothnagel HJ, et al. (2012) Structure of the chemokine receptor CXCR1 in phospholipid bilayers. Nature 491: 779783

41. Zhang C, Srinivasan Y, Arlow DH, Fung JJ, Palmer D, et al. (2012) Highresolution crystal structure of human protease-activated receptor 1 . Nature 492: 387-392.

42. Wang C, Jiang Y, Ma J, Wu H, Wacker D, et al. (2013) Structural basis for molecular recognition at serotonin receptors. Science 340: 610-614.

43. Wacker D, Wang C, Katritch V, Han GW, Huang XP, et al. (2013) Structura features for functional selectivity at serotonin receptors. Science 340: 615-619.

44. Ostopovici HL, Borota A, Gruia A, Mracec M, Rad-Curpan R, Mracec M (2010) $3 \mathrm{D}$ homology model of the a2b-adrenergic receptor subtype. Revue Roumaine de Chimie 55: 343-348.

45. Ostopovici-Halip L, CurpÄfn R, Mracec M, Bologa CG (2011) Structural determinants of the alpha2 adrenoceptor subtype selectivity. J Mol Graph Model 29: 1030-1038.

46. Laurila JM, Wissel G, Xhaard H, Ruuskanen JO, Johnson MS, et al. (2011) Involvement of the first transmembrane segment of human $\hat{I} \pm(2)$-adrenoceptors in the subtype-selective binding of chlorpromazine, spiperone and spiroxatrine. Br J Pharmacol 164: 1558-1572.

47. Thompson JD, Higgins DG, Gibson TJ (1994) CLUSTAL W: improving the sensitivity of progressive multiple sequence alignment through sequence weighting, position specific gap penalties and weight matrix choice. Nucleic Acids Res 22: 4673-4680.

48. Bhattacharya A, Tejero R, Montelione GT (2007) Evaluating protein structures determined by structural genomics consortia. Proteins 66: 778-795.

49. Sippl MJ (1993) Recognition of errors in three-dimensional structures of proteins. Proteins 17: 355-362.

50. Ballesteros JA, Weinstein $H$ (1995) Integrated methods for the construction of three dimensional models and computational probing of structure function relations in G protein-coupled receptors: Methods in Neurosciences. Academic Press, San Diego, CA.

51. Venkatachalam CM, Jiang X, Oldfield T, Waldman M (2003) LigandFit: a nove method for the shape-directed rapid docking of ligands to protein active sites. J Mol Graph Model 21: 289-307.

52. Ruuskanen JO, Laurila J, Xhaard H, Rantanen VV, Vuoriluoto K, et al. (2005) Conserved structural, pharmacological and functional properties among the three human and five zebrafish alpha 2-adrenoceptors. Br J Pharmacol 144 165-177.

53. Wang CD, Buck MA, Fraser CM (1991) Site-directed mutagenesis of alpha $2 \mathrm{~A}$-adrenergic receptors: identification of amino acids involved in ligand binding and receptor activation by agonists. Mol Pharmacol 40: 168-179.

54. Friesner RA, Banks JL, Murphy RB, Halgren TA, Klicic JJ, et al. (2004) Glide: a new approach for rapid, accurate docking and scoring. 1. Method and assessment of docking accuracy. J Med Chem 47: 1739-1749.

55. Halgren TA, Murphy RB, Friesner RA, Beard HS, Frye LL, et al. (2004) Glide: a new approach for rapid, accurate docking and scoring. 2. Enrichment factors in database screening. J Med Chem 47: 1750-1759.

56. Krovat EM, Steindl T, Langer T (2005) Recent Advances in Docking and Scoring. Curr Comput Aided Drug Des 1: 93-102.

57. Baldwin JM, Schertler GF, Unger VM (1997) An alpha-carbon template for the transmembrane helices in the rhodopsin family of $\mathrm{G}$-protein-coupled receptors. J Mol Biol 272: 144-164

58. Salminen T, Varis M, Nyrönen T, Pihlavisto M, Hoffrén AM, et al. (1999) Threedimensional models of alpha(2A)-adrenergic receptor complexes provide a structural explanation for ligand binding. J Biol Chem 274: 23405-23413.

59. Laurila JM, Xhaard H, Ruuskanen JO, Rantanen MJ, Karlsson HK, et al. (2007) The second extracellular loop of alpha2A-adrenoceptors contributes to the binding of yohimbine analogues. Br J Pharmacol 151: 1293-1304.

60. Frang H, Cockcroft V, Karskela T, Scheinin M, Marjamäki A (2001) Phenoxybenzamine binding reveals the helical orientation of the third transmembrane domain of adrenergic receptors. J Biol Chem 276: 31279 31284.

61. Sansuk K, Deupi X, Torrecillas IR, Jongejan A, Nijmeijer S, et al. (2011) A structural insight into the reorientation of transmembrane domains 3 and 5 during family A G protein-coupled receptor activation. Mol Pharmacol 79: 262269 .

62. Deupi X, Kobilka B (2007) Activation of G protein-coupled receptors. Adv Protein Chem 74: 137-166.

63. Gong B, Wang YT (2012) Directional gating of synaptic plasticity by GPCRs and their distinct downstream signalling pathways. EMBO J 31: 783-785.

64. Yao X, Parnot C, Deupi X, Ratnala VR, Swaminath G, et al. (2006) Coupling ligand structure to specific conformational switches in the beta2-adrenoceptor. Nat Chem Biol 2: 417-422.

65. Ahn KH, Bertalovitz AC, Mierke DF, Kendall DA (2009) Dual role of the second extracellular loop of the cannabinoid receptor 1: ligand binding and receptor localization. Mol Pharmacol 76: 833-842.

66. Morgan AA, Rubenstein E (2013) Proline: the distribution, frequency, positioning, and common functional roles of proline and polyproline sequences in the human proteome. PLoS One 8: e53785.

67. Bokoch MP, Zou Y, Rasmussen SG, Liu CW, Nygaard R, et al. (2010) Ligandspecific regulation of the extracellular surface of a G-protein-coupled receptor. Nature 463: 108-112.

68. Friesner RA, Murphy RB, Repasky MP, Frye LL, Greenwood JR, et al. (2006) Extra precision glide: docking and scoring incorporating a model of hydrophobic enclosure for protein-ligand complexes. J Med Chem 49: 6177-6196. 
Citation: Jayaraman A, Jamil K, Kakarala KK (2013) Homology Modelling and Docking Studies of Human $\alpha 2$-Adrenergic Receptor Subtypes. J Comput Sci Syst Biol 6: 136-149. doi:10.4172/jcsb.1000111

69. Kakarala KK, Jayaraman, A, Jamil K (2012) In silico analysis of Human and Zebra fish a-2 Adrenergic Receptors. Journal of Biology, Agriculture and Healthcare 2: 11-31.

70. Ruffolo RR Jr, Nichols AJ, Stadel JM, Hieble JP (1991) Structure and function of alpha-adrenoceptors. Pharmacol Rev 43: 475-505.

71. Insel PA, Tang CM, Hahntow I, Michel MC (2007) Impact of GPCRs in clinical medicine: monogenic diseases, genetic variants and drug targets. Biochim Biophys Acta 1768: 994-1005.

72. Peeters MC, van Westen GJ, Li Q, IJzerman AP (2011) Importance of the extracellular loops in $\mathrm{G}$ protein-coupled receptors for ligand recognition and receptor activation. Trends Pharmacol Sci 32: 35-42.
73. Shi L, Javitch JA (2002) The binding site of aminergic G protein-coupled receptors: the transmembrane segments and second extracellular loop. Annu Rev Pharmacol Toxicol 42: 437-467.

74. Lawson Z, Wheatley M (2004) The third extracellular loop of G-protein-coupled receptors: more than just a linker between two important transmembrane helices. Biochem Soc Trans 32: 1048-1050.

75. Storjohann L, Holst B, Schwartz TW (2008) A second disulfide bridge from the $\mathrm{N}$-terminal domain to extracellular loop 2 dampens receptor activity in GPR39. Biochemistry 47: 9198-9207. 